\title{
Effect of Deformation Temperature on Crystal Texture Formation in Hot Deformed Nanocrystalline $\mathrm{SmCo}_{5}$ Permanent Magnets
}

\author{
Q. Ma ${ }^{1,2}$, M. Yue ${ }^{1 *}$, W. C. Lv ${ }^{1}$, H. G. Zhang ${ }^{1}$, X. K. Yuan ${ }^{1}$, D. T. Zhang ${ }^{1}$, \\ X. F. Zhang ${ }^{2}$, J. X. Zhang ${ }^{1}$, and X. X. Gao ${ }^{3}$ \\ ${ }^{1}$ College of Materials Science and Engineering, Beijing University of Technology, Beijing 100124, China \\ ${ }^{2}$ School of Mathematics, Physics and Biological Engineering, Inner Mongolia University of Science \& Technology, \\ Baotou 014010, China \\ ${ }^{3}$ State Key Laboratory for Advanced Metals and Materials, University of Science \& Technology Beijing, Beijing 100083, China
}

(Received 30 June 2015, Received in final form 1 December 2015, Accepted 2 December 2015)

\begin{abstract}
In the present study, bulk anisotropic nanocrystalline $\mathrm{SmCo}_{5}$ magnets were prepared by hot deformation. The effect of deformation temperature on the texture and magnetic properties are presented, based on which the mechanism of plastic deformation and texture formation during the hot deformation process is discussed. Our analyses reveal that deformation temperature is one of the most important parameters that determine the texture of $\mathrm{SmCo}_{5}$ grains. We suggest that diffusion creep plastic deformation occurs during hot deformation, which is very sensitive to the energy gain provided by an increase in temperature.
\end{abstract}

Keywords : crystal texture, deformation temperature, EBSD, magnetic properties

\section{Introduction}

Cobalt-based magnetic materials have attracted considerable attention because of their large anisotropy field $\left(\mathrm{H}_{\mathrm{A}}\right)$, high saturation magnetizations $(\mathrm{Ms})$, and high Curie temperatures $\left(T_{C}\right)$. As the first generation of rare earth transition metal (RE-TM)-based permanent magnets, $\mathrm{SmCo}_{5}$ magnets possess extraordinarily high anisotropy (over $240 \mathrm{kOe}$ ), and nanocrystalline $\mathrm{SmCo}_{5}$ magnets show coercivity as high as $50 \mathrm{kOe}[1,2]$. Furthermore, the high $\mathrm{T}_{\mathrm{C}}$ and strong corrosion resistance of nanocrystalline $\mathrm{SmCo}_{5}$ magnets make them promising candidates for practical application at elevated temperatures [3-5]. Hot deformation is one effective way to obtain a crystallographic texture and, thereby, magnetic anisotropy in nanocrystalline permanent magnets. Gabay et al. [6] observed an enhanced (001) diffraction peak corresponding to the $\mathrm{SmCo}_{5}$ phase in hot deformed $\mathrm{Sm}_{17} \mathrm{Co}_{83}$ magnets, indicating a certain degree of crystallographic texture. Yue et al. [7] reported that significantly improved texture can be obtained in nanocrystalline $\mathrm{SmCo}_{5}$ alloys subjected to die upsetting at a very high degree of deformation (more than

(C)The Korean Magnetics Society. All rights reserved.

*Corresponding author: Tel: +86013701249783

Fax: +86013701249783, e-mail: yueming@bjut.edu.cn
$85 \%$ height reduction). However, the mechanism of plastic deformation and texture formation during the hot deformation process is not yet clear $[8,9]$. In this paper, the orientation texture of grains and their boundary planes in nanocrystalline $\mathrm{SmCo}_{5}$ anisotropic magnets are characterized using electron backscattered diffraction (EBSD). We then discuss the effect of deformation temperature on texture and magnetic properties.

\section{Experimental Procedures}

An $\mathrm{SmCo}_{5}$ master alloy was prepared by induction melting with $99.9 \%$ pure elements. An excess of Sm (10 $\mathrm{wt} \%$ ) was added to compensate for weight loss from evaporation. The ingot was crushed into blocks that were subjected to high-energy ball milling, which was carried out in an argon atmosphere for $5 \mathrm{~h}$. The milled powders were then hot compacted at $700{ }^{\circ} \mathrm{C}$ under $500 \mathrm{MPa}$, using spark plasma sintering (SPS), followed by die upsetting at $850-940{ }^{\circ} \mathrm{C}$ under $10-70 \mathrm{kN}$ with a height reduction of $60-90 \%$. The crystal structure of the magnets was studied by $x$-ray diffraction (XRD). The samples were then treated by metallographic polishing with diamond abrasives, and afterwards, EBSD measurements were performed using an EDAX Hikari high speed detector incorporated into an FEI Quanta 250 scanning electron microscope. 
The merged EBSD data were analyzed using the TSLOIM ${ }^{\mathrm{TM}}$ Analysis 5.3 software. Magnetic measurement was carried out with a Quantum Design physical properties measurement system. The density of both hot pressed and hot deformed magnets was examined by the Archimedes method. The result, $8.4 \mathrm{~g} / \mathrm{cm}^{3}$, is over $98 \%$ of the density of the alloy ingot.

\section{Results and Discussion}

Figure 1 shows the magnetic properties of hot deformed magnets as a function of deformation temperature. It shows that an increase in deformation temperature results in a gradual increase in saturation magnetizations (Ms) and remanence $\left(\mathrm{M}_{\mathrm{r}}\right)$, while the coercivity $\left(\mathrm{H}_{\mathrm{ci}}\right)$ drops.

The data in Fig. 1 indicate a strong magnetic anisotropy in hot deformed magnets using a deformation temperature of $940{ }^{\circ} \mathrm{C}$. This is a sign of enhanced magnetic crystallographic alignment with the increase in deformation temperature.

Figures 2(a) and 2(b) show TEM micrographs of hot deformed bulk anisotropic $\mathrm{SmCo}_{5}$ nanocomposite magnets made with deformation temperatures of $850^{\circ} \mathrm{C}$ and 940 ${ }^{\circ} \mathrm{C}$ and a deformation pressure of $70 \mathrm{kN}$. The microstructure was mainly composed of well-aligned plateletshaped $\mathrm{SmCo}_{5}$ grains 100-200 nm in thickness and 600$800 \mathrm{~nm}$ in length, which indicates that a strong c-axis texture of the $\mathrm{SmCo}_{5}$ phase was obtained by hot deformation. On the other hand, at a deformation temperature of $850{ }^{\circ} \mathrm{C}$, some $\mathrm{SmCo}_{5}$ equiaxial grains, which never

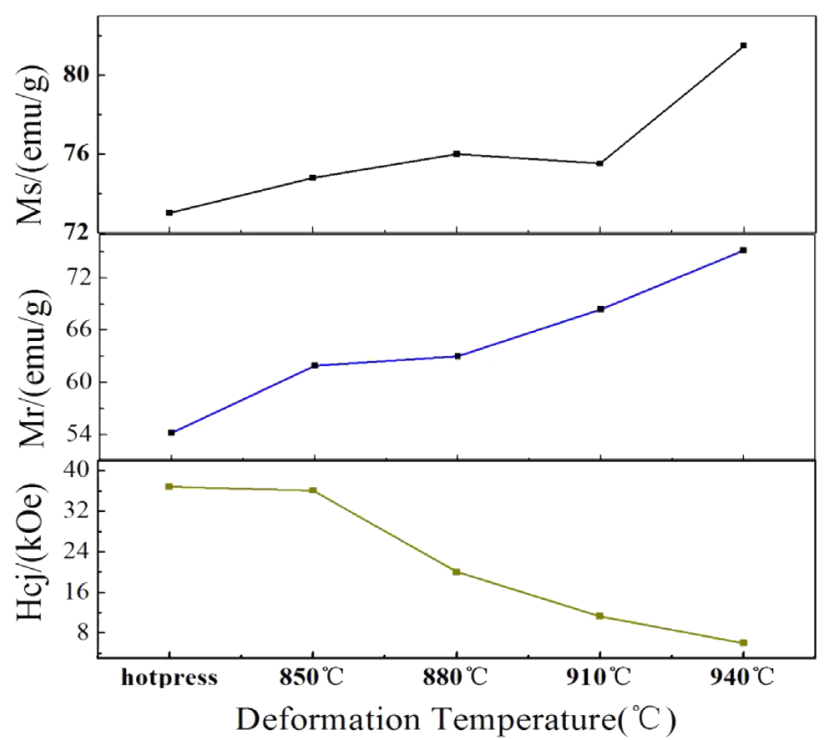

Fig. 1. (Color online) Magnetic properties of hot deformed bulk nanostructure $\mathrm{SmCo}_{5}$ permanent magnets with a pressure of $70 \mathrm{kN}$ and a height reduction of $90 \%$.

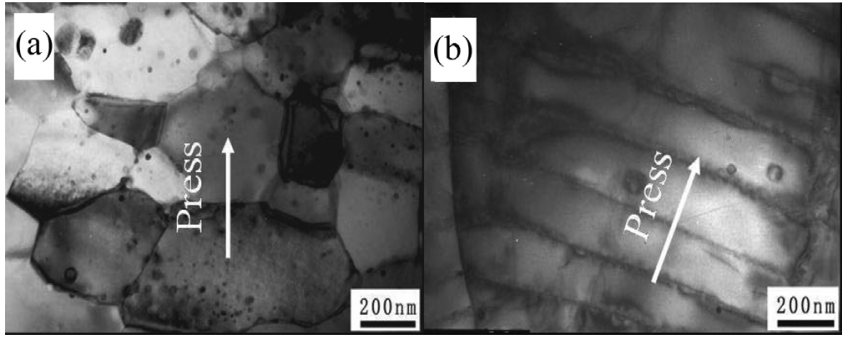

Fig. 2. TEM images of bulk nanostructure $\mathrm{SmCo}_{5}$ permanent magnets deformed under a temperature of $850{ }^{\circ} \mathrm{C}$ (a) and $940^{\circ} \mathrm{C}$ (b) and a deformation pressure of $70 \mathrm{kN}$.

change their shape even after the hot deformation process, can also be observed, mainly because of the inadequate deformation temperature.

In hot pressed magnets, the main diffraction peak is in the (111) plane, indicating a typical random orientation of the grains. After hot deformation, however, diffraction peaks such as (002) and (001) become dominant, indicating a strong c-axis crystallographic alignment of the $\mathrm{SmCo}_{5}$ phase. In order to characterize the crystallographic alignment semiquantitatively, the relative intensity ratio between the diffraction peaks of (002) and (111) of the hot deformed $\mathrm{SmCo}_{5}$ magnets prepared with different deformation conditions was calculated (Fig. 3). The relative intensity ratio of the hot pressed magnets is 0.26 , indicating random grain orientation. With the increase of deformation temperature from $850{ }^{\circ} \mathrm{C}$ to $940{ }^{\circ} \mathrm{C}$ and increase in pressure from $10 \mathrm{kN}$ to $70 \mathrm{kN}$, the relative intensity ratio increases linearly, suggesting crystallographic alignment. Under the same pressure, the ratio rapidly

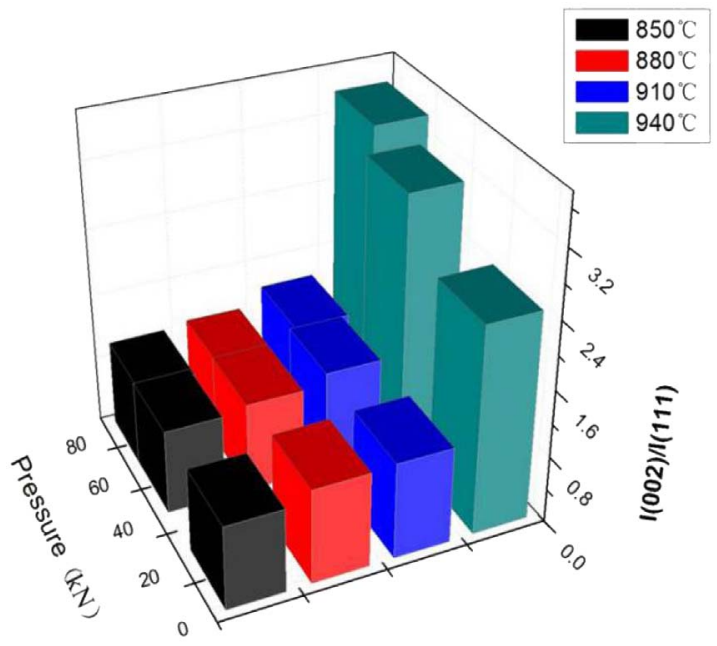

Fig. 3. (Color online) The relative intensity ratio between the (002) peak and the (111) peak in the XRD pattern of hot pressed and hot deformed bulk nanocrystalline $\mathrm{SmCo}_{5}$ permanent magnets. 
(a)

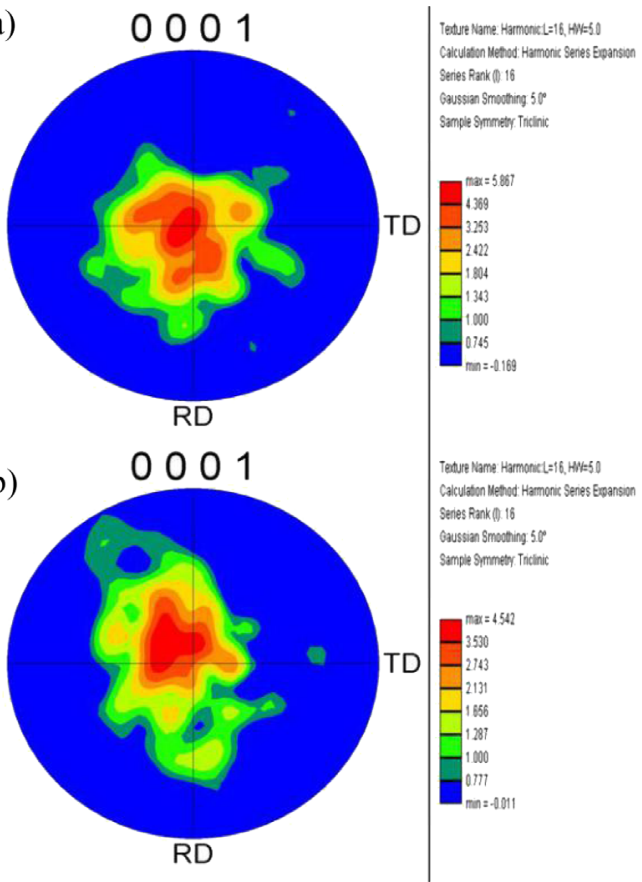

Fig. 4. (Color online) Pole figure of $\mathrm{SmCo}_{5}$ made with deformation temperatures of $940{ }^{\circ} \mathrm{C}$ (a) and $850{ }^{\circ} \mathrm{C}$ (b) and a deformation pressure of $70 \mathrm{kN}$.

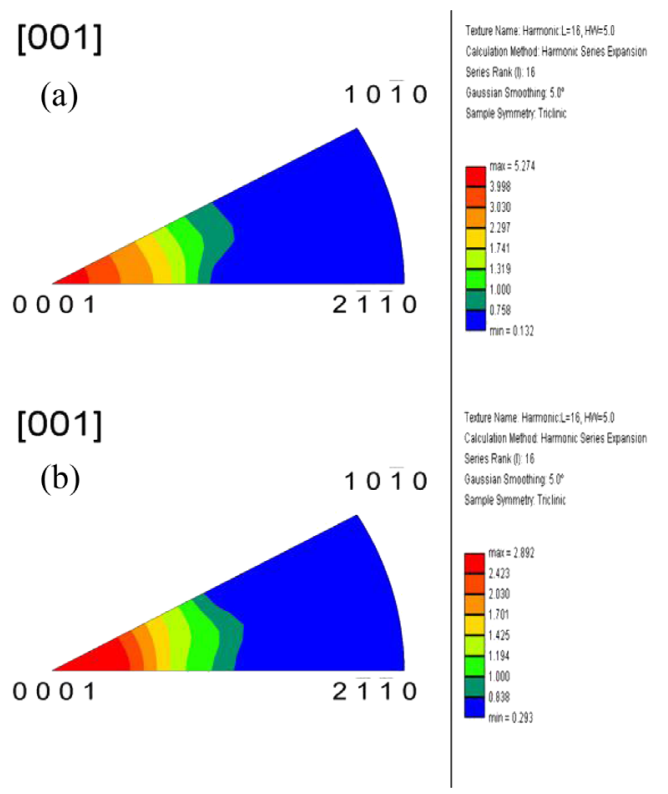

Fig. 5. (Color online) Inversepole figure of $\mathrm{SmCo}_{5}$ made with deformation temperatures of $940{ }^{\circ} \mathrm{C}$ (a) and $850{ }^{\circ} \mathrm{C}$ (b) and a deformation pressure of $70 \mathrm{kN}$.

increases with increasing deformation temperature. The sample hot deformed under $70 \mathrm{kN}$ at $940{ }^{\circ} \mathrm{C}$ shows a relative intensity ratio of 3.2 , which indicates a strong caxis texture.
The texture of $\mathrm{SmCo}_{5}$ samples deformed under different conditions is characterized by a $\{0001\}$ pole figure (PF) as shown in Fig. 4 and an inverse pole figure (IPF) as in Fig. 5. Figure 4 (a) shows a strong $\{0001\}$ orientation of $\mathrm{SmCo}_{5}$ grains, with frequencies of 3.6 Multiple of Random Distribution (MRD). Although the samples deformed under $940{ }^{\circ} \mathrm{C}$ and $850{ }^{\circ} \mathrm{C}$ have the same height reduction $(90 \%)$, the $\{0001\}$ orientation texture of the latter is not as good as the one shown in Fig. 4 (a). IPF charts show strong $\{0001\}$ orientations of $\mathrm{SmCo}_{5}$ grains deformed under $940{ }^{\circ} \mathrm{C}$, as illustrated in Fig. 5 (a). The frequency of the $\{0001\}$ orientation texture of $\mathrm{SmCo}_{5}$ deformed under $850{ }^{\circ} \mathrm{C}$ is only $2.9 \mathrm{MRD}$, as shown in Fig. 5 (b). Because texture is enhanced under high deformation temperatures, we suggest that a diffusion creep plastic deformation process occurs during hot deformation, which is very sensitive to the energy gain provided by a temperature increase. This further illustrates that texture formation is highly energy-dependent.

The rate at which temperature changes is one of the most important parameters for texture evolution during hot deformation. Figure 6 shows the XRD pattern of hot deformed bulk nanocrystalline $\mathrm{SmCo}_{5}$ permanent magnets made with different rates of temperature change. The peaks were obtained from the surface perpendicular to the direction of applied stress for all samples. The intensity of the (001) and (002) diffraction peaks becomes stronger compared to those of the hot pressed sample, and the faster the temperature changed, the stronger the intensity of the (001) peak became. A suitable temperature was obtained fastest with a temperature change of $60{ }^{\circ} \mathrm{C} / \mathrm{min}$, and diffusion increased with increasing temperature. Temperature dependence of the diffusion creep plastic

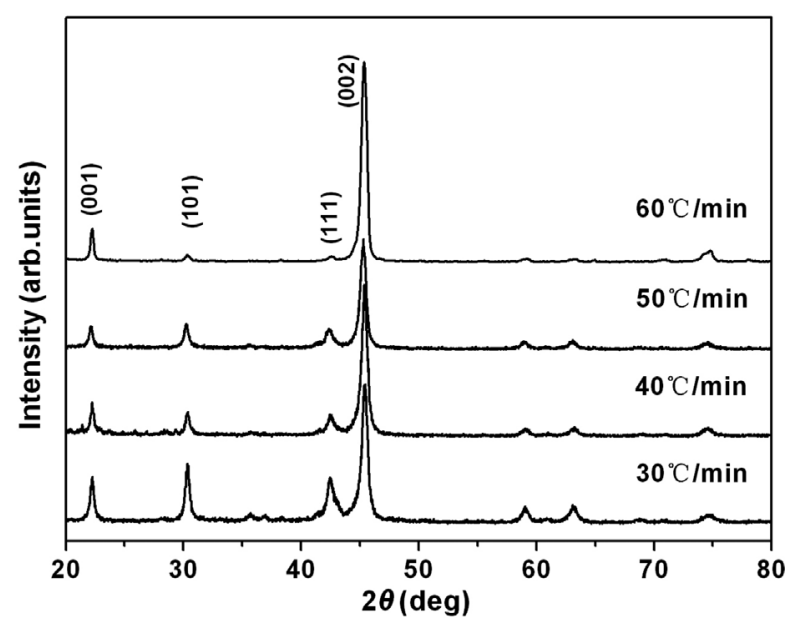

Fig. 6. XRD pattern of hot deformed bulk nanocrystalline $\mathrm{SmCo}_{5}$ permanent magnets with different rates of temperature change. 
deformation mechanism has been shown [10, 11]; therefore, we propose a possible diffusion creep plastic deformation mechanism for the hot deformation process. We conclude that deformation temperature plays an important role in the formation of c-axis crystal texture during hot deformation.

\section{Conclusions}

This work shows that the evolution of c-axis orientation textures in nanocrystalline $\mathrm{SmCo}_{5}$ magnets is closely correlated with energy gain during the hot deformation process. Temperature is one of the most important parameters for the texture of $\mathrm{SmCo}_{5}$ grains. Therefore, a possible diffusion creep plastic deformation mechanism of the hot deformation process is proposed, which may be vital information for further investigations of texture formation and property improvement in $\mathrm{SmCo}_{5}$ magnets.

\section{Acknowledgements}

This work was supported by the National Natural Science Foundation of China (51331003, 51471007), Beijing Natural Science Foundation (2152006), State Key Lab of Advanced Metals and Materials (2014-ZD07), and the Scientific Research Foundation for the Returned Overseas Chinese Scholars, State Education Ministry, and the Fundamental Research Foundation of Beijing Univer- sity of Technology, Key Laboratory of Integrated Exploitation of Bayan Obo Multi-Metal Resources.

\section{References}

[1] J. Ding, P. G. Mccormick, and R. Street, J. Alloys Compd. 191, 197 (1993).

[2] K. J. Strnat, Elsevier, Amsterdam. 4, 131 (1988).

[3] G. P. Zhao, F. Morvan, and X. L. Wan, Rev. Nanosci. Nanotech. 3, 227 (2014).

[4] B. Z. Cui, A. M. Gabay, W. F. Li, and M. Marinescuetal, J. Appl. Phys. 107, 09A721-1 (2010).

[5] B. Z. Cui, W. F. Li, and G. C. Hadjipanayis, Acta. Mater. 59, 563 (2011).

[6] A. M. Gabay, W. F. Li, and G. C. Hadjipanayis, J. Magn. Magn. Mater. 323, 2470 (2011).

[7] M. Yue, J. H. Zuo, and W. Q. Liu, J. Appl. Phys. 109, 07A711 (2011).

[8] W. Q. Liu, J. H. Zuo, M. Yue, W. C. Lv, D. T. Zhang, and J. X. Zhang, J. Appl. Phys. 109, 07A731 (2011).

[9] X. K Yuan, M. Yue, D. T. Zhang, T. N. Jin, Z. R. Zhang, J. H. Zuo, J. X. Zhang, J. Zhu, and X. X. Gao, CrystEngComm - Royal Society of Chemistry 16, 1669 (2014).

[10] P. Wollgramm, H. Buck, K. Neuking, A. B. Parsa, S. Schuwalow, J. Rogal, R. Drautz, and G. Eggeler, Mater. Sci. Eng. A 628, 382 (2015).

[11] W. Grtinberger, D. Hinz, A. Kirchner, K. H. Mtiller, and L. Schultz, J. Alloys Compd. 257, 293 (1997). 